\author{
Cadernos de \\ ESTUDOS Lingü̈ISTIICOS - (55.2), Campinas, Jul./Dez. 2013
}

\title{
O MST NO JORNAL HOJE UMA ANÁLISE DISCURSIVA
}

\author{
MAURINI DE SOUZA ${ }^{1}$ \\ UIARA CHAGAS SILVA²
}

\begin{abstract}
RESUMO: Este artigo pretende apresentar uma das formas de construção da imagem do Movimento dos Trabalhadores Rurais Sem Terra do Brasil (MST). Utilizando o viés da análise do discurso baseada na postura de Pêcheux (1997 e 2002), e Orlandi (1998; 2005; 2007), busca-se evidenciar a parcialidade adotada pela imprensa brasileira nas notícias sobre o MST. São analisadas, neste trabalho, notícias do Jornal Hoje, exibido pela Rede Globo de Televisão, do mês de abril, dos anos de 2006, 2008 e 2010, disponíveis em formato de texto no sitio do telejornal; objetiva-se identificar uma das formas de construção da imagem do MST enquanto sujeito político e ator social. As questões levantadas na AD francesa e a indagação quanto à postura unívoca da "isenção", apontada como característica do jornal, tendo como cenário os interesses que conduzem aos investimentos nas notícias sobre o MST no Jornal Hoje, regem a análise proposta.
\end{abstract}

PALAVRAS-CHAVE: Discurso jornalístico, Análise do Discurso, MST.

ABSTRACT: This article aims to identify ways of building an image of de Movement of Landless Rural Workers of Brazil (MST). Using the bias discourse analysis presented in the posture of Pêcheux (1997 and 2002) and Orlandi (1998, 2005, and 2007), this article seeks to demonstrate the bias adopted by the Brazilian press in coverage of the MST. In this paper the Jornal Hoje, Globo TV, news of the month of April in the years 2006, 2008 and 2010 are analyzed, available in text format in site of the newscast. From the perspective of discourse analysis and questions about the univocal discourse of Jornal Hoje, that describes itself like "neutral", this proposal wants to show the interests that guide the reports.

KEYWORDS: Journalistic Discourse. Discourse Analysis, MST.

Utilizar a teoria da Análise do Discurso Francesa (AD) como apoio para perceber a imagem do Movimento dos Trabalhadores Rurais Sem Terra (MST) no Brasil é uma forma de entender a questão agrária no pais. Em alguns contextos, Reforma Agrária significa distribuir terras a quem não tem: nesse caso, terras que pertencem ao governo e, por isso, distribuir. Existe ainda a concepção de Reforma Agrária como redistribuição de terras, ou seja, disponibilização de terras que pertencem a alguém para redistribuí-las. Reforma Agrária se insere em vários e

${ }^{1}$ Doutora em Estudos Linguísticos pela UFPR; professora da UTFPR - Curitiba. Coordena o grupo de estudos Comunicação Dialética e Questão Agrária Brasileira (UTFPR) - maurinis@yahoo.com.br.

${ }^{2}$ Especialista em Comunicação pela UTFPR. Graduada em Letras pela PUCPr. Participa do grupo de estudos Comunicação Dialética e Questão Agrária Brasileira (UTFPR) - uiara-ucs@hotmail.com. 
diferentes discursos, remete a vários sujeitos e nem todos na mesma formação discursiva. Faz ressoar uma memória discursiva em que esses diferentes discursos se confrontam, sendo, portanto, um tema válido para ser submetido à proposta da AD.

O Movimento dos Trabalhadores Rurais Sem Terra no Brasil, "o maior movimento social campesino da América Latina” (BRINGEL; FALERO, 2008, p.281) ou "o maior e mais importante movimento social do mundo" (CHOMSKY, 2009), tem como bandeira o combate à realidade histórica brasileira de concentração fundiária. Este artigo pretende identificar a visão sob a qual são apresentadas as notícias relacionadas ao MST no Jornal Hoje, telejornal da emissora de maior audiência do país, a Rede Globo de Televisão. O objetivo final é de identificar uma das formas de construção da imagem do MST enquanto sujeito político e ator social, a partir das noticias apresentadas sobre o Movimento no Jornal Hoje, no mês de abril dos anos de 2006, 2008 e 2010, disponíveis no endereço eletrônico do telejornal (http://jornalhoje.globo.com/).

A relevância do presente artigo se dá por envolver questões políticas e sociais que suscitam outros debates, além de ter o comprometimento de confrontar a parcialidade com a qual são divulgadas as notícias sobre o Movimento no referido telejornal, o que permite articular questões como manipulação de informação e manipulação de público pela mídia televisiva. Não há a pretensão de apresentar respostas para as questões propostas e menos ainda de sanar os diversos problemas: o que se pretende é iniciar aqui um estudo que pode se desdobrar em outras pesquisas, outras análises, e provocar a comunidade acadêmica a olhar para as questões sociais envolvendo o espaço rural brasileiro, a fim de incentivar a reflexão sobre a situação dessa região. O intuito, neste momento, é um primeiro olhar analítico para o corpus do trabalho e a obtenção de interpretações pautadas na área da $\mathrm{AD}$.

\section{MOVIMENTO DOS TRABALHADORES RURAIS SEM TERRA NO BRASIL (MST)}

O Brasil é uma das nações de maior desigualdade social do mundo (CARTER, 2009, p.27). Desigualdades sociais resultantes de profundas raízes históricas, principalmente na estrutura fundiária do país. As origens da questão agrária brasileira remontam ao século XVI, com o modelo de exploração empregado pelos portugueses que queriam extrair o máximo que a colônia pudesse oferecer. A concentração da propriedade da terra foi e ainda é motivo de conflitos e controvérsias, o que fomenta o estudo e o debate em torno da questão agrária brasileira.

Se a colonização brasileira se deu pelo viés agrário, com um modelo colonial que "se baseava em três elementos: grande propriedade, monocultura e trabalho escravo" (SOUZA, 2004, p.23), a história brasileira está repleta de manifestações e conflitos campesinos: revoltas como a de Canudos (1897, nordeste brasileiro) e do Contestado (1912-1916, sul do Brasil) marcaram significativamente a questão 
agrária do país. Ao longo do século XX, políticas de redistribuição fundiária foram adotadas em várias nações. A crescente urbanização no Terceiro Mundo, o aumento da produção agrícola com a introdução de tecnologias modernas, a expansão dos conglomerados de agribusiness global, entre outros fatores da época, contribuíram para a formação de um novo clima a respeito da redistribuição fundiária.

O MST, "um dos movimentos sociais mais duradouros da história" (CARTER, 2009, p. 37), foi instituído formalmente e em nível nacional em janeiro de 1984. Um ano mais tarde, o Brasil testemunhava a inauguração de um novo governo civil, sob a promessa de executar um amplo programa de reforma agrária.. Em meados da década de 1990, o MST já era considerado o maior movimento social da América Latina, e a reforma agrária tinha lugar na agenda pública do Brasil.

Após meados da década de 1990, o Movimento ganhou fama nacional como um dos principais críticos das políticas neoliberais e tornou-se forte voz em defesa do setor agrário. Nos últimos anos, o MST ganhou voz também em redes internacionais como o Fórum Social Mundial e a Via Campesina, uma coalizão de associações de lavradores familiares em 69 países.

O papel incisivo do MST na reivindicação pela redistribuição de terra tem sido alvo de aclamação por parte da esquerda política e de hostilidade por parte da ala conservadora da política brasileira, que rotula como "atos de terrorismo" as ocupações em massa organizadas pelo movimento ${ }^{3}$ em grandes propriedades rurais. As duas perspectivas se fundamentam no potencial revolucionário do Movimento que é, desde a sua gênese, uma associação de brasileiros de baixo poder aquisitivo e não pretende ser, portanto, nenhum conglomerado de "santos" ou uma sociedade de "demônios"4.

O que tange essa questão é justamente o fato de que parte do conhecimento e reconhecimento público do MST provém da mídia; em consonância ao caso analisado por Pêcheux (2002, p. 23), no qual esse canal tende a apresentar o acontecimento como algo unívoco, desprezando suas contradições; acredita-se que esse formato tendencioso contribua para que haja uma resistência, por parte do brasileiro, a reconhecer os diferentes lugares do Movimento na articulação da Reforma Agrária e/ou informar-se reflexivamente sobre as questões que tangem o universo de distribuição de terras neste país.

A escolha do mês de abril como foco deste artigo se dá devido ao enfoque para com o Movimento nesse mês, intitulado pelo próprio MST como "Abril Vermelho". Todo mês de abril, diversas ações são promovidas em todo território nacional; este período é importante, pois é uma forma de relembrar o episódio conhecido como Massacre de Eldorado do Carajás, ocorrido à beira da rodovia PA-275, próxima à cidade de Eldorado dos Carajás, sul do estado do Pará. O massacre se deu no dia 17 de abril de 1996, quando duas mil famílias marchavam para a sede do Incra na capital do estado, Belém, a fim de cobrar uma posição quanto à desocupação da Fazenda Macaxeira, de 42.448 hectares, utilizada para

\footnotetext{
${ }^{3}$ Desde a sua origem, o Movimento tem desenvolvido uma sofisticada organização popular, com presença em quase todo território nacional.

${ }^{4}$ Segundo estimativa de Carter (2009, p. 39), baseado em dados de 2007, o MST possui aproximadamente 1,14 milhão de membros.
} 
extração de madeira. O governo do Estado havia prometido assentar e prover alimentos para os assentados, porém, devido à morosidade governamental, as famílias iniciaram uma marcha de $800 \mathrm{~km}$ rumo à capital paraense. Ao bloquearem a estrada em forma de protesto, foram cercados por contingentes policiais sem identificação em seus uniformes, que começaram a disparar contra os manifestantes. O resultado desta operação foi: 19 mortos, 69 feridos, e 07 desaparecidos. Segundo o legista da Unicamp Nélson Massini, 13 dos mortos foram executados depois de rendidos (MORISSAWA, 2001, p.156). Os dois policiais condenados (de 150 acusados) tiveram ordem de prisão decretada em maio de 2012, após 16 anos do evento 5 .

\section{IMPRENSA E JORNAL HOJE}

O jornalismo é um dos campos mais abrangentes da cultura social e individual; no entanto, não é imune à subordinação à lógica comercial, e esta impõe suas limitações aos outros universos (BOURDIEU, 1997, p.81). Os índices de audiência são tão determinantes que influenciam nas formulações estratégicas não só do núcleo de jornalismo, mas da mídia em geral. A economia determina a abordagem do jornalismo, e isso acaba por influenciar campos da formação cultural de uma sociedade específica.

A Rede Globo de Televisão iniciou suas atividades no dia 26 de abril de 1965, fundada pelo empresário Roberto Marinho. Efetivou-se uma rede de emissoras afiliadas espalhadas por todo país no dia primeiro de setembro de 1969. O pioneirismo e a tradição no ramo das notícias transmitidas pela televisão facilitaram a aquisição das inovações tecnológicas, que surgiram ao longo dos anos, viabilizando coberturas mais presentes - ainda que em localizações geográficas longínquas, nenhum outro órgão de mídia tem o alcance da Rede Globo.

O Jornal Hoje, produzido e exibido pela Rede Globo de Televisão, vai ao ar todas as tardes, de segunda a sábado. É um dos telejornais mais antigos da emissora, estreado no dia $1^{\circ}$ de abril de 1971; o JH nasceu como uma revista diária, com matérias sobre arte, espetáculos e entrevistas. Em 1991 o telejornal sofreu algumas mudanças e passou a transmitir mais noticias, mas sem deixar de lado o seu "formato de revista". Atualmente o próprio JH se define: "com uma linguagem coloquial, sem perder a seriedade, o Jornal Hoje avança em busca de uma forma criativa de fazer revista na TV" (http:/g1.globo.com/jornal-hoje/noticia/2010/04/ historia-do-jornal-hoje). Sendo o telejornal um dos expoentes da comunicação de massa, é importante considerar, em uma análise, a efetivação da manipulação de públicos a partir dos grandes grupos de comunicação.

${ }^{5}$ Conf.: http://noticias.uol.com.br/politica/ultimas-noticias/2011ias/2011/04/17/apos-15-anosdois-unicos-condenados-pelo-massacre-de-eldorado-dos-carajas-continuam-soutos.htm 


\section{4- ANÁLISE DO DISCURSO E COMUNICAÇÃO}

"Todo enunciado é intrinsecamente suscetível de tornar-se outro, diferente de si mesmo (...)" Essa afirmação de Pêcheux (2002, p. 53) aponta para uma postura diametralmente oposta à que defende a língua como um sistema lingüístico autônomo, independente das relações ideológicas ${ }^{6}$; esse é o caráter da proposta francesa de análise do discurso, empregada neste estudo. A análise do discurso (AD) procura situar o texto em sua discursividade, como processo discursivo, tendo em vista que é em funcionamento que ele produz sentido; a proposta de Pêcheux (2002), compartilhada por Orlandi ${ }^{7}$, considera as diversas contradições das diferentes vozes dos enunciados como parte fundamental do acontecimento, entendendo que enunciados que "remetem (Bedeutung) ao mesmo fato (...) não constroem as mesmas significações $\left(\operatorname{Sinn}^{8}\right)$ " (Idem, p. 20), mas a significação relaciona-se, além das questões levantadas pela lingüística textual, às relações históricas e também políticas e suas conseqüências em um momento histórico e social especifico, uma vez que qualquer discurso é produzido em um panorama de alguma relação de poder. Esse aspecto faz parte da natureza dos discursos, que revelam a equivocidade do acontecimento, em contraste com a "univocidade lógica" (Idem, p. 23) adotada pela mídia no exemplo apontado pelo autor - essa univocidade, direcionada pelo ideológico, é a crítica deste artigo à mídia em questão.

As posturas ideológicas envolvidas no processo sócio-histórico da produção - reprodução do que se fala são responsáveis, portanto, pela formação do sentido do que é dito; dessa forma, ele não existe em si mesmo, de forma literal, mas é determinado por elas e pode mudar de sentido de acordo com as posturas dos que o proferem; as formações discursivas são, então, as projeções, na linguagem, das formações ideológicas (PECHEUX, 1997). Na mesma linha de Pêcheux está Orlandi (1998), quando afirma que "a multiplicidade do sentido é inerente à linguagem" (p.20); essa linguagem múltipla, portadora da equivocidade lógica, extrapola as intenções do enunciador, mas é limitada, no contexto de comunicação, à lógica de quem o acolhe; tal limitação relaciona-se aos pontos adotados para a análise das matérias do Jornal Hoje - relação discurso e ideologia; o dito, o não dito e o silêncio; quem e onde se enuncia como direcionadores do sentido e a importância do pré-construído - abordados na sequência.

É importante destacar que, apesar de exceder as intenções do enunciador, esse discurso é passível de análise justamente porque, sendo permeado/orientado pela e produzido em consonância com a ideologia, pode-se observar a tendência adotada por quem produz os enunciados como oriendadora da postura adotada/defendida por tal produtor. Sendo o telejornal um dos expoentes da comunicação de massa, deve-se considerar a efetivação da manipulação de públicos a partir dos grandes grupos de comunicação. Chomsky e Herman (2003) analisam o relacionamento

${ }^{6}$ Conferir em PECHEUX, 1997, p. 92.

${ }^{7} \mathrm{Na}$ "Nota ao Leitor" da obra de Pêcheux (2002).

${ }^{8}$ Bedeutung e $\underline{\text { Sinn }}$ poderiam, em alemão, remeter a significado ou valor e sentido ou intenção, respectivamente. 
da mídia com o poder econômico ou com quem o detém em A manipulação do público e alegam que "a mídia os serve bem como propagandeia em nome de poderosos interesses sociais que a controlam e financiam" (p.11). A publicidade é a principal fonte de renda das emissoras de TV, portanto, seria contraditório se fossem tratados assuntos de interesses contrários aos desses patrocinadores; sendo o jornalismo parte desse sistema, a análise tem a função de trazer à tona aspectos do seu discurso, evidenciando seu papel disseminador da ideologia dominante ${ }^{9}$.

Sendo assim, coloca-se em questão a postura que se espera do discurso jornalístico e a sua transparência. Nos princípios editoriais do JH, há o tópico "isenção”, quando o jornal se diz pautado na busca pelo "Maximo" de isenção possível (http:// g1.globo.com/principios-editoriais-das-organizacoes-globo.html\#isencao), o que se pode questionar sob a ótica de Pêcheux (1997), para quem a formação discursiva "determina o que pode e deve ser dito" dentro de uma conjuntura "determinada pelo estado da luta de classes" (p. 160). As questões levantadas na AD francesa, e a indagação quanto à postura unívoca dessa "isenção" tendo como cenário os interesses que conduzem aos investimentos nas notícias sobre o MST no Jornal Hoje, exibido pela Rede Globo de Televisão, permeiam a análise proposta.

\section{ANALISES}

Durante os meses de abril dos anos de 2006, 2008 e 2010, foram veiculadas, no Jornal Hoje, sete notícias em que o MST foi citado diretamente e três notícias em que a questão agrária é mencionada e são relevantes no contexto deste trabalho. Elas apareceram em sua versão televisiva e, posteriormente, foram reproduzidas na íntegra em seu sitio na web, com a transcrição exata da locução do âncora, da narração do repórter e das falas dos entrevistados. As notícias estavam disponíveis no formato de texto, pois o vídeo foi removido do site do telejornal. Assim, neste trabalho, as matérias foram analisadas apenas a partir do texto disponibilizado na página oficial do telejornal na internet, o que, é importante afirmar, constitui uma perda para esta análise, já que a postura do apresentador contribuiria para a formulação das considerações finais.

As notícias serão analisadas pelos seguintes critérios baseados nas propostas de AD de Pecheux/ Orlandi:

- Relação discurso e ideologia;

- O dito, o não dito e o silêncio;

- O significado depende de quem e de onde se enuncia;

- A importância do pré-construído.

\footnotetext{
${ }^{9}$ Sobre essa postura, conferir ARBEX JR (2001)
} 
Ainda serão considerados para a pesquisa aos principais critérios formais de noticiabilidade apontados pelo pesquisador Alexandre Barbosa (2012): notoriedade, proximidade, relevância, notabilidade, inesperado, e conflitos, controvérsias $^{10}$. As análises das noticias sobre o MST no Jornal Hoje foram formuladas utilizando como base esses critérios e a proposta fundamentada nas teorias da análise do discurso já descritas neste artigo.

As matérias encontradas são (título e subtítulo):

06/04/06 - MTA fecha estrada no Centro Oeste - Trabalhadores rurais acampam no meio da BR-364, que liga o Mato Grosso ao sul e sudeste do país. O congestionamento já chega a dez quilômetros.

06/04/06 - Ocupação no Paraná - Foram libertadas no início da tarde de quinta-feira 13 pessoas que estavam como reféns de integrantes do Movimento Sem-Terra (MST) em uma fazenda de Guarapuava (PR).

17/04/06 - Sem-terra denuncia - Um sem-terra foi à polícia de Carazinho na manhã desta segunda-feira dizer que foi expulso porque se negou a roubar uma cerca.

17/04/06 - Dez anos de massacre - Hoje completam dez anos do massacre de Eldorado do Carajás, no Pará. Os manifestantes prestam homenagem aos dezenove mortos e protestam contra a impunidade.

27/04/06 - Produtores rurais fazem manifestação - Os agricultores reclamam do baixo preço pago pela soja. A saca do produto está valendo menos por causa da queda na cotação do dólar.

28/04/06 - Protesto em Mato Grosso - Produtores de soja bloqueiam a BR163, em Lucas do Rio Verde, a 350 quilômetros de Cuiabá

16/04/08 - Protestos do MST - Trabalhadores sem-terra fizeram manifestações em vários estados pedindo o assentamento de 150 mil famílias.

17/04/08 - Protestos de trabalhadores sem-terra - Manifestações de integrantes do MST em vários estados interrompem o funcionamento de uma ferrovia, uma hidrelétrica e praças de pedágio.

17/04/08 - Desocupação de terra no Pará - A polícia deve cumprir na quintafeira a desocupação de uma fazenda invadida há um ano por cerca de 600 famílias de sem-terra no sudeste do Pará.

${ }^{10}$ Disponível em http://www.latinoamericano.jor.br/aulas/JORN_INF/noticiabilidade.pdf. Acesso em 28/04/2012. 
12/04/10 - Acusado de matar Dorothy Stang é julgado pela terceira vez no Pará - Advogado de defesa se negou a representar Vitalmiro Bastos.

As matérias na íntegra podem ser encontradas no site do telejornal.

\section{Relação discurso e ideologia:}

Para inserir essa questão na análise, é preciso trazer à tona a postura de Pêcheux, que avalia como erro a concepção de se "considerar as ideologias como idéias e não como forças materiais" (1997, p. 129) e a crença de que elas se originam nos sujeitos, defendendo que, ao contrário, os sujeitos se constituem a partir das ideologias, retomando a proposta de L. Althusser. A relação entre discurso e ideologia se evidencia quando são analisados os conceitos de formação ideológica e formações discursivas. Uma formação ideológica pode ser compreendida como o conjunto de representações das práticas institucionais de um grupo social, de suas idéias, revelando a compreensão que cada grupo tem do mundo, uma vez que não existem ideias fora da linguagem.

É com essa formação discursiva assimilada que o homem constrói seus discursos, que ele reage linguisticamente aos acontecimentos. Por isso, o discurso é mais o lugar da reprodução que o da criação (FIORIN,1993. p.32).

E reprodução dentro de uma formação ideológica, que rege, no caso analisado, as escolhas nas reportagens. A maioria das notícias se enquadra como sendo de conflitos/controvérsia dentro dos critérios formais de noticiabilidade. Mesmo sendo um mês em que há diversas manifestações dentro do Movimento, o que ganhou visibilidade no Telejornal em análise são eventos em que, de alguma maneira, a imagem do MST parece ser desprivilegiada.

Em discursos como o utilizado na reportagem de 06/04/06 - "Ocupação no Paraná" - é possível identificar o tom pejorativo dado ao Movimento, quando se informa uma invasão a uma fazenda (o MST defende que se use a palavra ocupação, cujo sentido é condizente com a proposta do movimento e o contexto social em que se encontra ${ }^{11}$ ), e diz que Armados com foices (...), integrantes do MST fizeram 13 reféns (o Movimento defende que foices não são armas, mas utensílios de trabalho do homem do campo; essa informação não está contida na matéria). O discurso é muito próximo com o de reportagens policiais sobre criminosos; o uso das palavras invasão é uma escolha que remete à formação discursiva de quem produz a notícia em questão, assim como reféns e Armados. Além disso, o "agente" da ação, "integrantes do MST", apaga quaisquer características equívocas de identidade do sujeito que, assim como o acontecimento, é apresentado com “a mesma univocidade lógica” (PÊCHEUX, 2002, p. 23), incoerente com as

11 “Portanto, errado falar que houve invasão do imóvel pelos atuais ocupantes. Quem é o invasor é aquele que se diz proprietário sem legitimidade.” (Disponível em http://www.ecodebate. com.br/2009/04/25/invasao-ou-ocupacao-de-terras-quem-e-o-vilao-nesta-historia-artigo-de-delzedos-santos-laureano/ Acesso em 08.08.2012. 
características de um acontecimento envolvendo interesses sociais, econômicos e políticos, fruto de uma história marcada por conflitos. O advérbio muita caracterizando a negociação também indica a formação do produtor do discurso, já que não é informativo, mas opinativo em "depois de muita negociação"

Da mesma maneira, na reportagem de 17/04/06 - "Sem-terra denuncia" - a palavra roubar não faz parte do discurso do entrevistado, mas aparece no enunciado da notícia. Novamente há o uso de uma palavra com conotação criminosa, o que remete a questionar a formação discursiva e ideológica que forja a realidade transmitida por meio das reportagens do $\mathrm{JH}$ a respeito do MST.

Para contribuir com esta análise, foi selecionada uma das notícias que estão inseridas dentro do que serão denominadas aqui de "notícias do campo", sem que o MST seja citado: a de 27/04/06 - Produtores rurais fazem manifestação, complementada em 28/04/06, numa inserção de cerca de 10 segundos com o título Protesto em Mato Grosso. A diferença na escolha das palavras que constroem o enunciado é bastante significativa em comparado com as notícias que citam diretamente o MST. Desde a escolha da palavra manifestação para descrever o evento até a entrevista com um dos produtores, pode-se perceber que a abordagem dada à noticia não tem um cunho "policial" mesmo sendo citada a presença da polícia no evento. Inserções como "Os caminhoneiros que passam pela BR-163 com destino a Rondônia e Pará, principal corredor de exportação de grãos de Mato Grosso, vão ter que enfrentar protestos já que a rodovia foi interditada " e "Nem a liminar da Justiça Federal que determina a liberação da rodovia, intimida os produtores" (grifos nossos) indicam uma postura crítica aos manifestantes, o que aponta para a mesma formação ideológica contrária às manifestações no campo brasileiro, mas com palavras menos enfáticas do que as observadas nas matérias em que o MST é articulador dos eventos.

Essa opção aponta para a multiplicidade de contrastes presentes nessa relação discurso/ideologia: não se trata de um embate entre duas forças antagônicas, mas um quadro complexo de antagonismos e agonismos em diversas - e imensuráveis proporções tão complexas e mutantes quanto as relações sociais que as circundam.

É importante destacar ainda as escolhas das palavras invasão e roubar como destoantes em um veículo de mídia que se compromete a transmitir uma informação que se divulga imparcial; a escolha desses termos mobiliza efeitos de sentido que colocam em conflito o discurso, considerando que, para a $\mathrm{AD}$, é através dos discursos que se constroem os traços ideológicos quem moldam a realidade.

\section{$\underline{O}$ dito, o não dito e o silêncio:}

Parece evidente que os mecanismos lingüísticos sejam formados por aquilo que é verbalizado, pelo que é escrito, pelo que é dito. Porém, o que não é dito também tem importância e é fundamental na construção dos significados. Orlandi (1993) discute o silêncio e, diferentemente do que se imagina, ele não deve ser confundido com ausência de palavras como um momento da não significação. Segundo a autora, o silêncio também pode ser pensado como a respiração da significação, lugar de recuo necessário para que se possa significar, para que o sentido faça sentido. 
A reportagem de 17/04/06 - "Dez anos de massacre" - é a única que faz menção ao "Abril Vermelho" noticiando uma homenagem às vitimas do massacre de Eldorado dos Carajás e o pedido por justiça para os assassinos. Em todas as outras, a causa motriz para os eventos é silenciada, apontando para uma condução ao esquecimento desse fato.

Outra questão que remete ao "não dito" nas matérias é: mesmo sendo o maior mote da luta do MST, a reforma agrária não é citada em nenhuma noticia sobre ocupações ou conflitos do JH em que o movimento é mencionado durante o período delimitado nesta pesquisa - a única menção se dá na notícia sobre os dez anos do massacre de Eldorado. Reforma agrária é silenciada como problema no campo brasileiro - na mídia, os problemas se restringem a políticas de governo (e não de Estado) e a ações do MST. É nesse sentido que se faz valer a colocação de Orlandi quanto ao silêncio - o não dito. Identifica-se esse silêncio quanto à não menção das causas do MST, uma vez que não são ditos os motivos que explicariam as ações do Movimento.

Voltando à reportagem de 17/04/06 - "Sem-terra denuncia...", observa-se ai também o silêncio na postura da imprensa quanto às fontes. Enquanto que o acusador do MST expõe acusações graves (estupro de menores e porte de armamentos pesados), que poderiam ser ratificados ou não pela polícia local, não houve nenhuma informação oficial sobre a acusação, contrariando o código de ética do jornalismo, que, no artigo 12 , orienta o jornalista a "II - buscar provas que fundamentem as informações de interesse público"'12. Além disso, o desmentido da acusação, por parte do líder local do MST, foi apresentado de forma indireta, após o comentário de que "não quis gravar entrevista", seguido de "Por telefone, negou as acusações e disse que Cleomar saiu porque tinha problemas de relacionamento e com bebida alcoólica". Ora, as informações transmitidas pelo telefone foram uma entrevista e deveriam ter igualdade de valor no contexto da reportagem tanto o silêncio sobre o final das investigações da acusação quanto a redução do dito pela segunda fonte (MST) são exemplares para apontar tendenciosidade na matéria em questão.

A relação com as fontes, aliás, é um exemplo do silêncio que pode ser observado no córpus desta análise: quase na totalidade, o trabalhador rural sem terra não é fonte das informações; a quebra desse paradigma se dá quando, como exemplifica a reportagem acima, esse trabalhador é fonte de denúncia ao Movimento.

\section{O significado depende de quem e de onde se enuncia:}

A AD leva em consideração o local em que o sujeito do discurso enuncia, qual a sua função no ato da enunciação e em que condições este discurso foi produzido. Estas são questões relevantes, uma vez que são determinantes de significado. Segundo Orlandi:

${ }^{12}$ Disponível em http://www.fenaj.org.br/federacao/cometica/codigo_de_etica_dos_jornalistas brasileiros.pdf. Acesso em 15 .06.2013. 
O sentido não existe em si, mas é determinado pelas posições ideológicas colocadas em jogo no processo sócio-historico em que as palavras são produzidas. As palavras mudam de sentido segundo as posições daqueles que as empregam. Elas "tiram" seu sentido dessas posições, isto é, em relação às formações ideológicas nas quais essas posições se inscrevem. (1999, p.42-43.)

Os sentidos são regulados socialmente, de modo que a mesma expressão produz sentidos diferentes segundo quem enuncia e a posição que ocupa, uma vez que o sentido não se depreende da materialidade discursiva, mas de uma série de relações a serem estabelecidas entre o enunciado, seu enunciador e o amplo contexto que envolve a enunciação.

A plataforma primeira de onde os discursos do JH são proferidos é a Rede Globo de Televisão. Duas motivações se encontram em relação ao jornalismo e à sustentação da Rede Globo: se por um lado há uma mandatória ética de constante busca pela isenção de posicionamento político, partidário e religioso ${ }^{13}$, pelo outro, enquanto empresa que, na prática, visa o lucro ${ }^{14}$, continua dependendo totalmente de seus anunciantes e, de certa forma, sendo influenciada ou não por determinações econômicas em diferentes níveis. É desta plataforma, de empresa capitalista que responde a interesses múltiplos, antes de veículo midiático e jornalístico, que são proferidos os discursos do $\mathrm{JH}$, conforme as matérias apontadas.

As reportagens de 16/04/08 - Protestos do MST e 17/04/08 - Protestos de trabalhadores sem-terra são sobre protestos. Eles são relatados pelo Telejornal com ressalva aos prejuízos de alguma forma causados pela manifestação - "e quebraram um vidro", funcionários da Caixa Econômica que "não puderam trabalhar", usuários de trem que fizeram fila para "pegar o dinheiro de volta", articulação nos pedágios para que os motoristas "passassem sem pagar a tarifa (...) pelo menos 1500 motoristas se beneficiaram da invasão e passaram sem pagar nada". Em nenhum momento fica evidenciada a causa do Movimento ou mesmo o que especificamente os integrantes do MST buscavam com aquelas manifestações, sem uma análise das condições de vida do trabalhador do campo brasileiro ou da necessidade, já prevista em lei, de que a terra cumpra uma função social. O que permeia o texto é o lugar ocupado pelo enunciador com visão capitalista: MST gera prejuízo.

13 "I - a divulgação da informação precisa e correta é dever dos meios de comunicação e deve ser cumprida independentemente da linha política de seus proprietários e/ou diretores ou da natureza econômica de suas empresas;". Código de ética do jornalista, Cap. I, Art. 2. (Disponível em http:// www.fenaj.org.br/federacao/cometica/codigo_de_etica_dos_jornalistas_brasileiros.pdf. Acesso em 15 $.06 .2013)$.

${ }^{14}$ Como concessão do Estado, as emissoras de televisão pertencem a instituições de Terceiro Setor (fundações, associações); pela legislação brasileira, estas não devem ter lucro; o que se observa, porém, é que as emissoras, tanto de televisão como de rádio, no Brasil, estão dentre as empresas mais lucrativas do país (conf. http://donosdamidia.com.br/inicial). 


\section{A importância do pré-construído:}

Utilizando o termo proposto por Paul Henry, Pêcheux define "préconstruído" como aquilo que remete a "uma construção anterior e exterior, mas sempre independente, por oposição ao que é "construído" pelo enunciado" (1997, p.99). Uma análise precisa, portanto, considerar as construções independentes dos enunciados, cientes de que elas poderão irromper, em maior ou menor medida, no momento da elocução. Orlandi (1998, p. 31) apresenta esse termo como parte das questões em que a memória se insere nos estudos do discurso:

E, nessa perspectiva, ela é tratada como interdiscurso. Este é definido como aquilo que fala antes, em outro lugar, independentemente. Ou seja, é o que chamamos memória discursiva: o saber discursivo que torna possível todo o dizer e que retorna sob a forma do pré-construído, o já-dito, que está na base do dizível, sustentando cada tomada da palavra.

Esse elemento permeia todas as reportagens referidas neste trabalho. A visão e a noção que se tem do MST é forjada na medida em que o próprio telejornal ${ }^{15}$, outros jornais da emissora ${ }^{16}$ e parte do jornalismo veiculado pela grande mídia nacional ${ }^{17}$ materializam, por meio da reafirmação, em diferentes formas, o conceito de que o movimento é destrutivo e danoso.Tal abordagem acaba por tornar-se o concreto, a realidade do momento em que a notícia é transmitida, o que só é possível devido às construções anteriores a respeito do tema e que, no momento em que a notícia é enunciada, são levadas em consideração.

Assim, quando se questiona o expectador do JH quanto ao seu conhecimento do Movimento dos Trabalhadores Rurais sem Terra, ele responde que conhece o MST, mesmo sem ter vivenciado nenhum episódio ou lido algum trabalho científico, pois a sequência de matérias sobre o assunto atua como uma experiência anterior com o tema.

As manifestações no campo fazem parte da história brasileira, marcada, desde a dominação portuguesa, pelo controle centralizado de terras (a distribuição do Brasil entre quinze nobres portugueses e seus herdeiros - capitanias hereditárias - se deu no início do século XVI). O golpe militar de 1964 reprimiu os movimentos rurais que haviam conquistado a Lei da Reforma Agrária no governo João Goulart, que seria promulgada em 15 de abril, duas semanas após a tomada de poder. Na época, havia duas propostas de desenvolvimento econômico para o campo - o que sugeria o investimento em tecnologia (menos produzindo mais) e o que pretendia a distribuição das terras devolutas (públicas) para a população sem terra (mais produzindo mais); os

${ }^{15}$ Conferir, como exemplo, reportagens "Por engano", 07.02.2001; "Sem Terra estão presos", 25.03.2002; "Sem-terra na pista", 21.05.2003; Bloqueio de sem-terra, 06.04.2004; Voz de prisão, 16.02.2005. Disponiveis em http://busca.globo.com/Busca/redeglobo/?query=jornal+hoje + mst\&orde $\underline{\text { nacao }}=$ ascending \&offset $=1 \&$ xargs $=\&$ formato $=\&$ requisitor $=$ redeglobo $\&$ aba $=$ todos $\&$ filtro $=\& o n=$ false \& formatos $=443 \% 2 \mathrm{C} 437 \% 2 \mathrm{C} 5 \% 2 \mathrm{C} 1 \% 2 \mathrm{C} 0 \% 2 \mathrm{C} 0 \% 2 \mathrm{C} 0 \% 2 \mathrm{C} 0 \% 2 \mathrm{C} 0 \% 2 \mathrm{C} 0 \% 2 \mathrm{C} 0 \&$ filtroData $=\&$ dataA $=\&$ dataB $=$. Acesso em 17.06.2013.

${ }^{16}$ Conferir artigo de Ferreira e Resende (2009), MST e Jornal Nacional: uma relação dialética? Disponível em http://informativo.ct.utfpr.edu.br/artigos/136.pdf. Acesso em 17.06.2013.

${ }^{17}$ Conferir: MOURÂO, 2011 
militares investiram na tecnologia como articuladora do progresso na agricultura. Assim, ainda com os problemas sociais gerados pela concentração de terras ${ }^{18}$, durante o último governo militar, em que a repressão se abrandou, o homem do campo começou a se manifestar e se organizar em movimentos, como o MST. Hoje, o MST é o maior movimento de luta não-armada do mundo (estimativa de 1,14 milhão de pessoas por CARTER, 2011, p. 39) em um país que detém a maior concentração de terras do planeta ${ }^{19}$.

O Jornal Hoje da Rede Globo de Televisão é representativo como órgão jornalístico em concessão pública e, para tanto, deve se pautar pelo Código de ética do jornalista e estar sujeito à lei $\mathrm{n}^{\circ} 8.987$, de 13 de fevereiro de $1995^{20}$, que dispõe sobre as concessões. No entanto, observa-se que a função de "a construção, total ou parcial, conservação, reforma, ampliação ou melhoramento de quaisquer obras de interesse público“ (Cap. I, Art. 2. Par. III. Grifo nosso), determinado pela legislação, é colocada em segundo plano quando se trata da proteção de interesses não públicos, mas de determinados grupos privados. Caberia ao jornalismo independente, "isento", buscar o trato dialético dessas questões consideradas de relevância à comunidade ou, como prevê a legislação, de "interesse público", levando à população as informações como parte da complexidade ideológico-social em que se materializam. Os acontecimentos utilizados como motes das reportagens são expostos em completa dissociação com a questão histórica brasileira, assim como as opções econômicas, políticas e sociais deste país, que fazem parte deles - é como se surgissem naquele momento e, como se, isolados, pudessem ser concebidos fora de qualquer contexto.

Como essa postura é padrão e tem como defesa o tempo reduzido das reportagens - elas duram entre um e quatro minutos -, turva a reflexão e impõe como reflexos perfeitos ("verdadeiros") as informações transmitidas sobre esses acontecimentos. A isso chamamos manipulação.

Esse pré-construído, decorrente de anos de vivência, leituras, debates, pesquisas e interação com pessoas ligadas ao jornalismo e, em menor grau, à questão agrária brasileira, regeu as escolhas efetuadas neste artigo. Os critérios desenvolvidos vêm ao encontro da percepção de que a univocidade aparente no relato das informações tem a função de dissimular a relação intrínseca entre a formação discursiva e a ideológica que mantém a estrutura (e toda sua materialidade) social deste país. A proposta aqui desenvolvida não se pretende maniqueísta, mas dialética, e a importância da utilização da Análise do Discurso é justamente pelo fato de que esses estudos permitem olhar o enunciado sob a orientação de que a complexidade, a equivocidade, os contrastes e as contradições habitam o discurso, e é ele que deve ser analisado.

\footnotetext{
${ }^{18}$ Segundo dados de 2005, do Banco Mundial, mais da metade da população do campo no Brasil vive abaixo da linha da pobreza (CARTER, 2010, p.57).

19 "Menos de 50 mil proprietários rurais possuem áreas superiores a mil hectares e controlam $50 \%$ das terras cadastradas. Cerca de $1 \%$ dos proprietários rurais detêm em torno de $46 \%$ de todas as terras". (Disponível em http://www.social.org.br/relatorios/relatorio002.htm. Acesso em 15.06.2013).

${ }^{20}$ Disponível em http://www.planalto.gov.br/ccivil 03/leis/18987cons.htm. Acesso em 20.06.2013 . O Brasil, teoricamente, é o segundo em concentração de terras, mas como o primeiro, o Paraguai, tem brasileiros como proprietários de suas terras,
} 
Dessa forma, o ator social que emerge desse discurso pode ser delineado como um grupo coeso, unívoco e silencioso (o "sem-terra"entrevistado e que se pronunciou diretamente havia sido "expulso"do movimento), unido por meio de atos violentos realizados (porte de armas pesadas, reféns e realização de atos ilegais) e sofridos, no confronto de Eldorado dos Carajás. Como sujeito político, o MST que emerge por meio do discurso do Jornal Hoje não é civilizado, incompetente no cumprimento das normas sociais que regem a cidadania e os tempos modernos/ pós-modernos (interromper o "funcionamento de uma ferrovia, uma hidrelétrica e praças de pedágio"); ele parte de um lugar em que a ilegitimidade é a regra (o "sem-terra" foi expulso porque se negou a "roubar uma cerca") e, justamente por isso, a impunidade é recorrente e se apresenta na forma da morosidade no cumprimento da lei (protesto contra 10 anos de impunidade e, em outra matéria, a demora de um ano para a polícia realizar a desocupação).

Existe hoje um considerável corpus de analises sobre o MST pelo viés da análise do discurso, porém trabalhos analisando o discurso da mídia televisiva ainda não são muitos e este artigo pretende se inserir como um primeiro "ensaio" para tal e incentivar a temática da questão agrária como fonte de pesquisa.

\section{$\overline{\text { REFERÊNCIAS }}$}

ARBEX JR, José. Showrnalismo. A notícia como espetáculo. São Paulo: Casa Amarela, 2001.

BARBOSA, Alexandre. Disponível em http://www.latinoamericano.jor.br/aulas/JORN

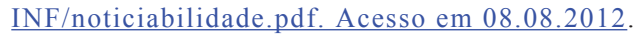

BOURDIEU, Pierre, Sobre a televisão. Trad. Maria Lúcia Machado. Rio de Janeiro: Jorge Zahar Ed. 1997.

BRINGEL, Breno e FALERO, Alfredo. "Redes transnacionais de movimentos sociais na América Latina e o desafio de uma nova construção socioterritorial.'In Caderno $C R H$, vol 21, n. 53. Salvador, 2008. Disponível em www.scielo.br/scielo.php?pid=S0103-49792008000200006\&script=sci_ arttext. Acesso em 08.08.2012.

CARTER, Miguel. Combatendo a desigualdade social: o MST e a reforma agrária no Brasil. São Paulo: Editora UNESP, 2010.

CHOMSKY. Noam e HERMAN, Edward. Manufacturing Consent: the political economy of the mass media. New York: Pantheon Books, 1989. . (2009) "Noam Chomsky e Gilmar Mendes". In http://www.gazetadopovo.com.br/blog/ caixazero/?id=867653. Acesso em 22.03.2013.

FERREIRA, Douglas Ciriaco e RESENDE, Mario. MST e Jornal Nacional: uma relação dialética? Curitiba: UTFPR, 2009. Disponível em http://informativo.ct.utfpr.edu.br/artigos/136.pdf. Acesso em 17.06.2013.

MORISSAWA, Mitsue. A história da luta pela terra e o MST. São Paulo: Expressão popular, 2001.

MOURÃO, Monica. Vozes Silenciadas. A cobertura da mídia sobre o Movimento dos Trabalhadores Rurais Sem Terra durante a Comissão Parlamentar Mista de Inquérito. São Paulo: Intervozes, 2011. 
Cadernos de ESTUDOS LINGǘISTICOS (55.2) - Jul./Dez. 2013

ORLANDI, Eni. Análise de Discurso: princípios e procedimentos. Campinas: Pontes, 1998. Discurso e Leitura. Campinas: Cortez, 2005. Análise de Discurso: princípios e procedimentos Campinas: Pontes 2005. Disponível em http://pt.scribd.com/doc/21564382/Eni-Orlandi-Analise-Discurso.

PÊCHEUX, Michel. O discurso. Estrutura e acontecimento. Trad. Eni Orlandi. Campinas: Pontes, 1997.

Semântica e discurso: uma crítica à afirmação do óbvio. Campinas: UNICAMP, 2002.

REDE GLOBO DE TELEVISAO - JORNAL HOJE. Disponível em http://g1.globo.com/jornal-hoje/ noticia/2010/04/historia-do-jornal-hoje.

SOUZA, Eduardo Ferreira de. Do silêncio à satanização: o discurso de Veja e O MST. São Paulo: Annablume, 2004. 
Ficha técnica

$\begin{aligned} \text { Divulgação } & \text { Publicações IEL-UNICAMP } \\ \text { Montagem } & \text { Publicações IEL } \\ \text { Editoração } & \text { In Design CS5 } \\ \text { Formato } & 16 \times 23 \mathrm{~cm} \\ \text { Mancha } & 12 \times 19 \mathrm{~cm} \\ \text { Tipologia } & \text { Time new roman } \\ \text { Papel } & \text { Miolo: pólen soft } 75 \mathrm{~g} / \mathrm{m} \\ & \text { Capa: cartão supremo } 250 \mathrm{~g} / \mathrm{m} \\ \text { Impressão e acabamento } & \text { Oficinas Gráficas da UNICAMP } \\ \text { Numero de páginas } & 191 \text { páginas } \\ \text { Tiragem } & 200 \text { exemplares }\end{aligned}$

